\title{
Bancadas virtuais e storyboards com ilustrações microscópicas representativas como recursos no estudo da Mecânica
} Quântica

\author{
Robson Trevisan*, Agostinho Serrano de Andrade Neto**
}

\section{Resumo}

Buscamos, neste estudo, analisar como o uso combinado de bancadas virtuais e storyboards podem promover a compreensão de teóricos do professor de física em formação acerca do fenômeno da dualidade onda-partícula de entidades quânticas nos arranjos experimentais da dupla fenda e do IMZ. Assim, verificamos a possibilidade do seu estabelecimento em uma corrente interpretativa da MQ. A condução desta investigação converge para a assimilação das interpretações individuais dos estudantes, após ações didáticas mediadas por recursos externos de processamento de informações. Para tanto, optamos pela afluência de dois fundamentos teóricos, a saber, a Teoria da Mediação Cognitiva (TMC), por sua leitura acerca da mediação hipercultural, e a Modelização Científica de Mario Bunge, devido a seu juízo em relação à estruturação de conhecimento de modo racional. Após as análises processadas diante dos testes e dos gestos descritivos coletados das imagens de vídeo gravadas durante entrevistas, os resultados foram levantados. Constatamos que as instruções didáticas forneceram possibilidades aos licenciandos para analisar ontologicamente e epistemologicamente, de diferentes formas, um mesmo resultado empírico previsto pelo formalismo da MQ. Também identificamos a prevalência de uma postura dualista realista na interpretação dos alunos.

Palavras-chave: Ensino de Física. Mecânica Quântica. Bancadas Virtuais. Storyboards. Report Aloud.

- Mestre em Ensino de Ciências e Matemática (ULBRA). Doutorando em Ensino de Ciências e Matemática (ULBRA). Professor da Faculdade da Serra Gaúcha (FSG). E-mail: robsontrevi@gmail.com

* Doutor em Física (USP). Professor do Programa de Pós-Graduação em Ensino de Ciências e Matemática da Universidade Luterana do Brasil (ULBRA). E-mail: asandraden@gmail.com 


\section{Introdução}

As experiências cotidianas e os cursos introdutórios da física clássica promovem aos alunos prospectivas realistas compostas pela localidade e um significativo determinismo dos fenômenos da natureza. Contudo, a desenvolução da Mecânica Quântica (MQ), tomando bases rigorosamente científicas no início do século XX, não só levou os cientistas a impasses em relação às teorias bem estabelecidas na época devido à incorporação do indeterminismo, da probabilidade e da não-localidade para os fenômenos físicos, como também alterou expressivamente o modo científico de pensar.

$\mathrm{Na}$ literatura dirigida ao ensino de Física, encontra-se um número relevante de resultados que apontam dificuldades de alunos de ensino médio, graduação e pós-graduação no aprendizado de conteúdos medulares da $\mathrm{MQ}$, sendo que uma considerável parte desses obstáculos, no entendimento dos fenômenos quânticos fundamentais, vinculam-se a uma compreensão conceitual inconsistente, muito em razão da sua natureza não intuitiva e abstrata (FISCHLER; LICHTFELDT, 1992; IRESON, 2000; OLSEN, 2002; MONTENEGRO; PESSOA JR, 2002; PEREIRA; OSTERMANN; CAVALCANTI, 2009; WUTTIPROM et al., 2009; AKARSU, 2010; AYENE; KRIEK; DAMTIE, 2011; MARSHMAN; SINGH, 2015, BAILY; FINKELSTEIN, 2015; MARIES; SAYER; SINGH, 2017). Essas dificuldades conceituais/interpretativas geralmente aparecem mesmo quando os alunos adquirem com sucesso as habilidades procedimentais, de modo que, em alguns casos, eles são capazes de resolver problemas tradicionais da MQ que exijam o formalismo matemático, mas não respondem a questões fundamentais e qualitativas sobre o comportamento dos objetos quânticos em sistemas básicos.

Nessa ótica, um importante exemplo a ser enfatizado é o estudo da dualidade onda-partícula, em que a carga conceitual e as teorias interpretativas são essenciais para a apreensão e resolução do fenômeno em diversos contextos e arranjos experimentais (PESSOA JR, 1997; BAILY; FINKELSTEIN, 2010; AYENE; KRIEK; DAMTIE, 2011; CHEONG; SONG, 2013; MARIES; SAYER; SINGH, 2017), sobretudo no experimento da dupla fenda, um fenômeno definitivamente impossível de se explicar de modo clássico, além de conter em si o cerne da Física Quântica, segundo Feynman, Leighton e Sands (2008). 
Em seu estudo sobre o desdobramento e a validação das Quantum Interactive Learning Tutorials (QuILTs), Singh (2008) reforça a importância de ferramentas computacionais que permitem a visualização de experimentos virtuais, o que auxilia os alunos na sua construção particular dos conceitos quânticos, mantendo-os envolvidos no decurso da aprendizagem. A autora ainda ressalta o feedback apropriado dado pela ferramenta, após a previsão de um caso particular, e as tentativas de preenchimento de um hiato entre o formalismo quantitativo abstrato da MQ e a compreensão qualitativa necessária para explicar e prever diversos fenômenos físicos.

Nesta direção, podemos mencionar os softwares como experimentos virtuais que representam o Interferômetro Virtual de Mach-Zehnder e o Experimento da Dupla-Fenda, constantemente presentes em pesquisas que abrangem instruções didáticas direcionadas ao ensino da MQ (MÜLLER; WIESNER, 2002; SINGH, 2008; PEREIRA; OSTERMANN; CAVALCANTI, 2009; KOHNLE et al., 2015; MARSHMAN; SINGH, 2016; MARIES; SAYER; SINGH, 2017; TREVISAN; SERRANO, 2018).

Contudo, em um estudo recente (TREVISAN, 2016), verificou-se que as bancadas virtuais não se mostraram eficazes para uma nova aquisição de drivers $^{1}$ e modelos mentais microscópicos como contributivos para o processamento imagístico cerebral ocorrer, pois os softwares não fornecem estimativas de possíveis representações do objeto quântico ao longo do setup experimental. Esta é uma das características (DOERR, 1997) dos "experimentos virtuais", em contraponto às "simulações conceituais". Enquanto o segundo se permite apresentar representações conceituais utilizadas pelos cientistas - bem como o que ocorre macroscopicamente em um experimento -, o primeiro se limita a apresentar unicamente o que é observado em um experimento.

Em virtude do panorama estabelecido, Baily e Finkelstein (2015) defendem maior ênfase em fornecer aos alunos mecanismos conceituais e de linguagem para identificar e articular suas próprias intuições e crenças sobre o mundo microscópico. Nosso movimento de estudo dirigiu-se à construção e emprego de uma atividade didática orientada ao ensino da dualidade onda-partícula, com destaque para a compreensão de conceitos e teorias, e o reconhecimento das principais correntes interpretativas na análise do comportamento do objeto quântico (fóton e elétron) ao longo das configurações experimentais da Dupla Fenda e do IMZ.

A atividade didática é composta por softwares enquanto experimentos virtuais que representam a Dupla Fenda e o IMZ, e materiais em forma de storyboards 
como mediadores hiperculturais e socioculturais no ensino de MQ. Os storyboards apresentam representações que, organizadas, configuram a construção dos modelos científicos alusivos às conjecturas para cada interpretação da $\mathrm{MQ}$, sendo quatro as principais, buscando, assim, expor diferentes pontos de vista para a explicação dos resultados observados no experimento da dupla fenda. As sequências de representações foram desenvolvidas justamente para preencher a lacuna que se refere às representações do comportamento do mundo microscópico.

A proposta didática foi implementada em duas instituições de ensino superior, nos cursos de Licenciatura em Física, durante duas disciplinas introdutórias da MQ.

Em particular, o desdobramento dos nossos resultados concentram-se em dois aspectos relevantes para o ensino: (i) As potencialidades do uso combinado de experimentos virtuais e storyboards para o ensino da dualidade onda-partícula através da compreensão dos experimentos da dupla fenda e do IMZ. (ii) Como essas mediações podem favorecer o preenchimento de lacunas interpretativas nestes contextos experimentais fundamentais da MQ.

De forma a embasar as conjunturas que deram sustentabilidade teórica à investigação conduzida, apresentamos a seguir os referencias epistemológicos adotados.

\section{A teoria da mediação cognitiva}

Primeiramente, apresentamos a Teoria da Mediação Cognitiva (TMC) (SOUZA, 2004) levando em consideração a sua percepção e explicação para o movimento de Mediação e Processamento Extracerebral de informações, como um instrumento que contribui para o desenvolvimento cognitivo, ao passo que nosso cérebro incorpora de maneira crescente e cumulativa aspectos dos mecanismos externos (ambiente), passando das formas mais simples para as formas mais complexas de mediação. Ademais, acreditamos que essa escolha seja apropriada também pelo seu importante diagnóstico acerca da influência cultural das tecnologias digitais, principalmente com o uso dos computadores e seus softwares, em razão de elas serem as ferramentas hiperculturais (no formato de bancadas virtuais) que empregamos durante as atividades direcionadas ao ensino de conceitos sobre a dualidade onda-partícula.

A TMC pressupõe que o aprendizado do sujeito depende substancialmente do processamento de informações, e que o cérebro humano por si só não é suficiente para explicar grande parte da performance cognitiva, desta forma, pode-se conceber 
o envolvimento de outros mecanismos de processamento de informação no processo de cognição. Além disso, "O processo pelo qual os seres humanos dependem de estruturas externas, a fim de complementar o processamento de informações feito por seus cérebros (cognição extracerebral), é chamado pela TMC de Mediação" (SOUZA et al., 2012, p. 2, tradução nossa).

A Figura 1 descreve resumidamente como acontece o processamento cognitivo através de mediações com arranjos do ambiente, encarregados por proporcionarem uma competência complementar de processamento de informações.

Figura 1: O processamento cognitivo por mediação externa.

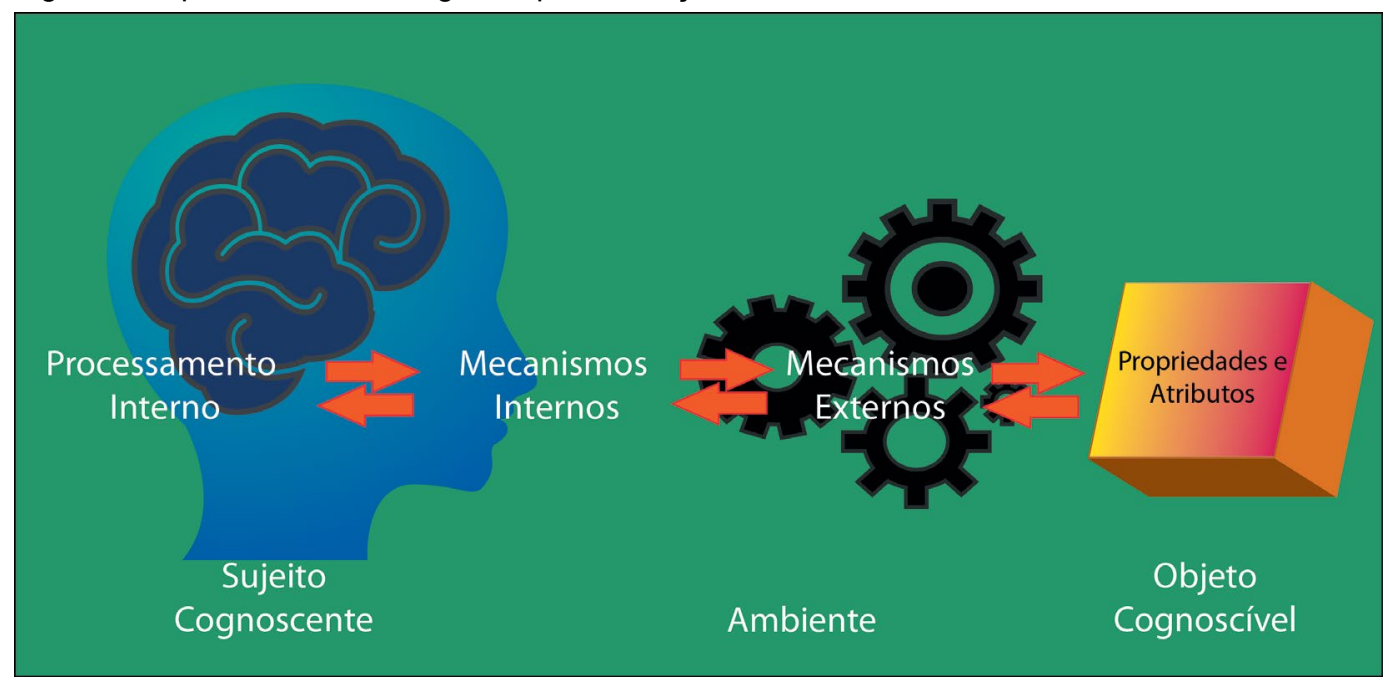

Fonte: Adaptado de Souza (2004).

Nessa perspectiva, acentua-se a dimensão do processo, pelo fato de que o cérebro, para garantir a mediação cognitiva com um mecanismo externo, como já mencionado, formula novas competências específicas que permitem a comunicação com o mecanismo externo em questão. Segundo Souza (2004), a aquisição de conhecimentos é resultado de um ganho de processamento de informações, oriundo da mediação que fora estabelecida, sendo que esse processamento adquirido se mantém mesmo que a conexão com o mecanismo externo seja interrompida.

Com base nesses aspectos, considera-se que a mediação cognitiva ocorre como função necessária ao impulsionamento da inteligência, relacionando os processos interior e exterior à estrutura cognitiva, sendo os drivers os intermediários entre o 
conjunto de conhecimentos que o indivíduo detém dentro de si com as habilidades que lhe permitam o acesso e a aplicação de mecanismos externos, visando a aquisição de conhecimentos e, consequentemente, o desenvolvimento da sua estrutura cognitiva. Em suma, os drivers promovem a mediação com estruturas do ambiente.

Considerando todos os aspectos teóricos mencionados, percebe-se a cognição humana como um elaborado de mecanismos interiores e exteriores de processamento de informações que, em conjunto, constroem um complexo sistema organizado.

\section{A modelização científica bungeana}

A opção pelas ideias racionalistas de Bunge a respeito dos Modelos Científicos deve-se pela sua maneira de conceber e alcançar a formação de relações entre teoria e resultados empíricos. Na perspectiva assumida por Bunge (1974), a modelização é um método legítimo na constituição do conhecimento teórico pelo pensamento. Essa visão filosófica e epistemológica nos orientou na construção da ferramenta sociocultural - os storyboards. Estes apresentam um agrupamento de representações, que, organizadas, configuram a construção dos modelos científicos alusivos às conjecturas para cada interpretação principal da $\mathrm{MQ}$, buscando, assim, expor diferentes pontos de vista para a explicação dos resultados observados no experimento da dupla fenda.

Neste contexto, observamos que o movimento da modelização se inicia com a composição de um objeto-modelo descrito pela esquematização, caracterização e simplificação em certo grau de um sistema ou de um caso adotado como real. O momento seguinte do processo é a elaboração do modelo teórico, no qual se busca determinar o comportamento e as disposições dos mecanismos presentes no objeto-modelo. De um modo geral, os modelos são constituídos por proposições, das mais simples até as mais elaboradas, tendo como função dar sentido e conduzir todas as estruturas presentes nos objetos-modelos, que representam os objetos reais. Em outros termos, a teoria geral é propicia a explicação de um objeto-modelo que produz um modelo teórico da situação/fenômeno estudado.

Desta forma, os modelos são estruturados mediante a carência de estabelecer conexões entre teorias e resultados experimentais. Pietrocola (1999) reforça que, no olhar bungeano, as teorias em si mesmas são insuficientes, uma vez que, como abstrações realizadas pelo raciocínio e pela intuição dos sujeitos, não se aplicariam às coisas reais. Em contrapartida, a resultância dos experimentos está mais pró- 
xima à realidade, e, no entanto, sozinhos, são incapazes de suscitar conhecimento. "Desta aparente dicotomia entre teórico e empírico, é introduzida a modelização como instância mediadora" (PIETROCOLA, 1999, p. 222).

Considerando o dimensionamento deste cenário, Bunge manifesta que a modelização é o método efetivo para se apreender e internalizar a realidade pelo pensamento, ou seja, é o processo de "converter coisas concretas em imagens conceituais (objetos-modelos) cada vez mais ricas e expandi-las em modelos teóricos progressivamente complexos e cada vez mais fiéis aos fatos" (BUNGE, 1974, p.30). Nesse sentido, Pietrocola (1999) aponta que, para Bunge, os modelos são considerados a natureza da atividade científica. Portanto, a integração da modelização científica ao ensino de Física pode proporcionar a orientação de ações didáticas nas quais os estudantes compreendam a realidade e representem-na a partir de teorias mais gerais.

Enfim, concebemos que o propósito essencial do entrelaçamento da TMC com os Modelos Científicos de Bunge é ascender subsídios conceituais que esclareçam tanto a mediação e o processamento das informações pelo cérebro, quanto à forma racional crítica para asserções de conhecimento acerca de sistemas reais.

\section{As mediações responsáveis pelas instruções didáticas}

Para iniciar a construção desta proposta didática implementada, levamos em consideração resultados observados nas publicações da área nas últimas duas décadas. Um dos principais pontos levantados pela literatura, que nos estimulou a desenvolver esta investigação, foram as dificuldades da compreensão conceitual apresentadas pelos estudantes em cursos introdutórios de MQ. Tem-se observado que os estudantes que reproduzem algoritmos de resolução com êxito são aprovados nos componentes curriculares, mesmo não atingindo uma compreensão dos conceitos em relação aos problemas solucionados.

Em relação às concepções e posturas epistemológicas expressas pelos alunos, estudos apontam resultados que inclinam-se para o predomínio de uma conduta clássica realista no instante de interpretar os resultados observados em arranjos experimentais reais e de pensamento, como os experimentos de Stern-Gerlach da dupla fenda e do IMZ, o que acarreta em imprecisões na compreensão de conceitos e princípios essenciais, como aos relacionados à natureza ontológica de partículas clássicas, luz e elétrons. Levantamos resultados apontando as dificuldades dos aca- 
dêmicos na assimilação de conceitos relacionados com a função de onda, processos de medição, valores esperados e o princípio da superposição. (MONTENEGRO; PESSOA JR, 2002; PEREIRA; OSTERMANN; CAVALCANTI, 2009; WUTTIPROM et al., 2009; AKARSU, 2010; BAILY; FINKELSTEIN, 2010; AYENE; KRIEK; DAMTIE, 2011; MARSHMAN; SINGH, 2015, BAILY; FINKELSTEIN, 2015; MALGIERI; ONORATO; DE AMBROSIS, 2017; MARIES; SAYER; SINGH, 2017).

Os estudos anteriores também levantam as potencialidades dos softwares computacionais no ensino de conteúdos introdutórios da MQ, ou seja, as contribuições destas tecnologias digitais para a compreensão dos fenômenos quânticos (PEREIRA; OSTERMANN; CAVALCANTI, 2009; KOHNLE et al., 2015; MARSHMAN; SINGH, 2016; MARIES; SAYER; SINGH, 2017). No entanto, como já mencionado na introdução deste manuscrito, estes softwares, sobretudo os que simulam o arranjo experimental da dupla fenda e o IMZ, não costumam acrescentar representações de cunho interpretativo, deixando lacunas interpretativas a respeito dos resultados apresentados após a simulação, a cargo de serem mentalmente preenchidas pelos estudantes, segundo as suas concepções construídas.

Neste tocante, buscamos desenvolver um objeto de aprendizagem em forma de storyboard para fornecer representações alusivas às quatro interpretações fundamentais da MQ e discutir conceitualmente os resultados disponibilizados para as configurações do arranjo experimental da dupla fenda. O material foi construído por uma transposição dos conceitos abordados conforme trabalhos de Pessoa Jr (2006). Dito isso, as ilustrações que idealizam o comportamento do objeto quântico pelas diferentes interpretações assimiladas são apresentadas. Nossa pesquisa tem aporte teórico em Bunge (1974) para os modelos científicos, e, desse modo, demonstramos os objetos-modelos concatenando-os ao modelo teórico que prevê seu comportamento em uma teoria mais abrangente.

Isso posto, consideramos que as representações e as ilustrações dos fenômenos quânticos que respeitam as conjecturas das principais correntes da MQ podem preencher um hiato interpretativo e favorecer a apreensão de conceitos sobre fenômenos quânticos tradicionais, os quais manifestam dualidade onda-partícula dos objetos quânticos. Um dos argumentos fundamentais da escola imagística sobre o funcionamento mental é que as representações são essenciais para o processamento cerebral, sobretudo por apresentarem a informação de forma condensada na contribuição à cognição (MOREIRA, 1996). Do mesmo modo, é possível que a ausência 
representativa adequada em grau microscópico prejudique a evolução conceitual. Especialmente em relação à teoria quântica, que apresenta variadas interpretações para um mesmo grupo de fenômenos, é provável que a viabilização de representações e drivers microscópicos correspondentes a interpretações diversificadas seja importante, didaticamente falando.

A seguir, serão apresentados os mecanismos externos de processamento de informações, descritos pelos experimentos virtuais e storyboards com representações microscópicas representativas.

\section{As bancadas virtuais}

Como mecanismos externos de mediação nas instruções didáticas, as ferramentas hiperculturais escolhidas são dois softwares computacionais interativos que simulam os arranjos experimentais da Dupla Fenda e o Interferômetro de Mach-Zehnder. Ambas simulações foram testadas em estudos anteriores e apresentaram resultados positivos em termos de ensino e aprendizagem em cursos introdutórios de $\mathrm{MQ}$, tanto em âmbito nacional quanto internacional.

Contém todo o mistério da MQ, essa é a descrição de Feynman, Leighton e Sands (2008) para o arranjo experimental da dupla fenda. Esse experimento foi desenvolvido por Thomas Young por volta do ano de 1802, mostrando que a luz se comportava como uma onda, porque os fenômenos da difração e da interferência, observados por Young com seu aparato experimental, eram características exclusivamente ondulatórias. A Fig. 2 apresenta o esquema da dupla fenda, utilizado durante as atividades propostas aos licenciandos em física. Isso foi obtido através de um software livre ${ }^{1}$, desenvolvido pelo Physics Education Research Group of the University of Munich. 
Figura 2: O experimento virtual da dupla fenda.

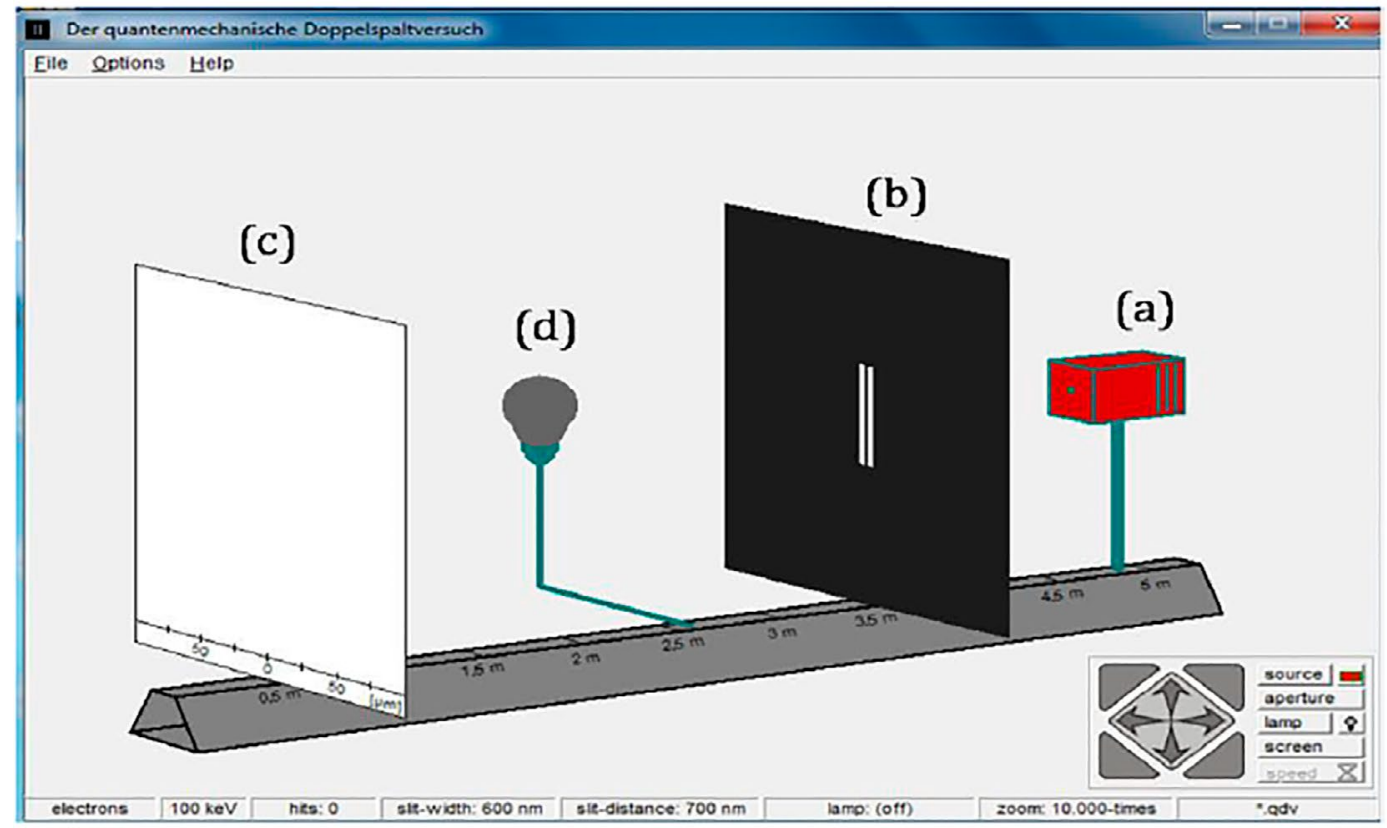

Fonte: Imagem extraída do software.

O arranjo é composto basicamente (a) por uma fonte emissora, com a capacidade de lançar objetos macroscópicos, como projéteis, objetos quânticos, como elétrons e fótons, e também feixes de luz; (b) por um primeiro anteparo contendo duas fendas, nas quais o espaçamento entre ambas e suas espessuras são ajustáveis; (c) por um segundo anteparo, que absorve e detecta a posição onde o objeto emitido pela fonte o colide; e (d) por uma lâmpada entre os anteparos, que quando ligada possibilita a visualização dos elétrons em seus percursos.

Foram abordadas duas configurações do experimento. O regime clássico, subdividido em duas situações, uma com a fonte emitente de projéteis macroscópicos e outra com a emissão de feixes de luz. E o regime quântico com a fonte emitente de elétrons ou fótons individuais, isto é, uma segunda entidade quântica só é emitida após a primeira chegar no anteparo. Este regime também foi subdividido em dois arranjos, com e sem a presença de um detector.

A segunda bancada virtual empregada remete ao "interferômetro de Mach-Zehnder” (IMZ), desenvolvido no século XIX. Reforça-se que este trabalho utilizou, 
ao longo das atividades desenvolvidas com os licenciandos em física, uma versão virtual do interferômetro de Muller e Wiesner, obtida em software livre ${ }^{3}$.

O esquema do IMZ está exposto na Fig. 3, composto por dois espelhos semi-refletores $\left(\mathrm{S}_{1}\right.$ e $\left.\mathrm{S}_{2}\right)$. Esses espelhos são comumente chamados de divisores de feixes, pois transmitem $50 \%$ da luz incidente e refletem os outros 50\%. Há dois espelhos "comuns" $\left(\mathrm{E}_{1}\right.$ e $\mathrm{E}_{2}$ ) que refletem $100 \%$ da luz incidente, há também um anteparo/ detector (D), no qual as imagens dos padrões são formados após a detecção da luz incidente.

Figura 3: Interferômetro de Mach-Zehnder.

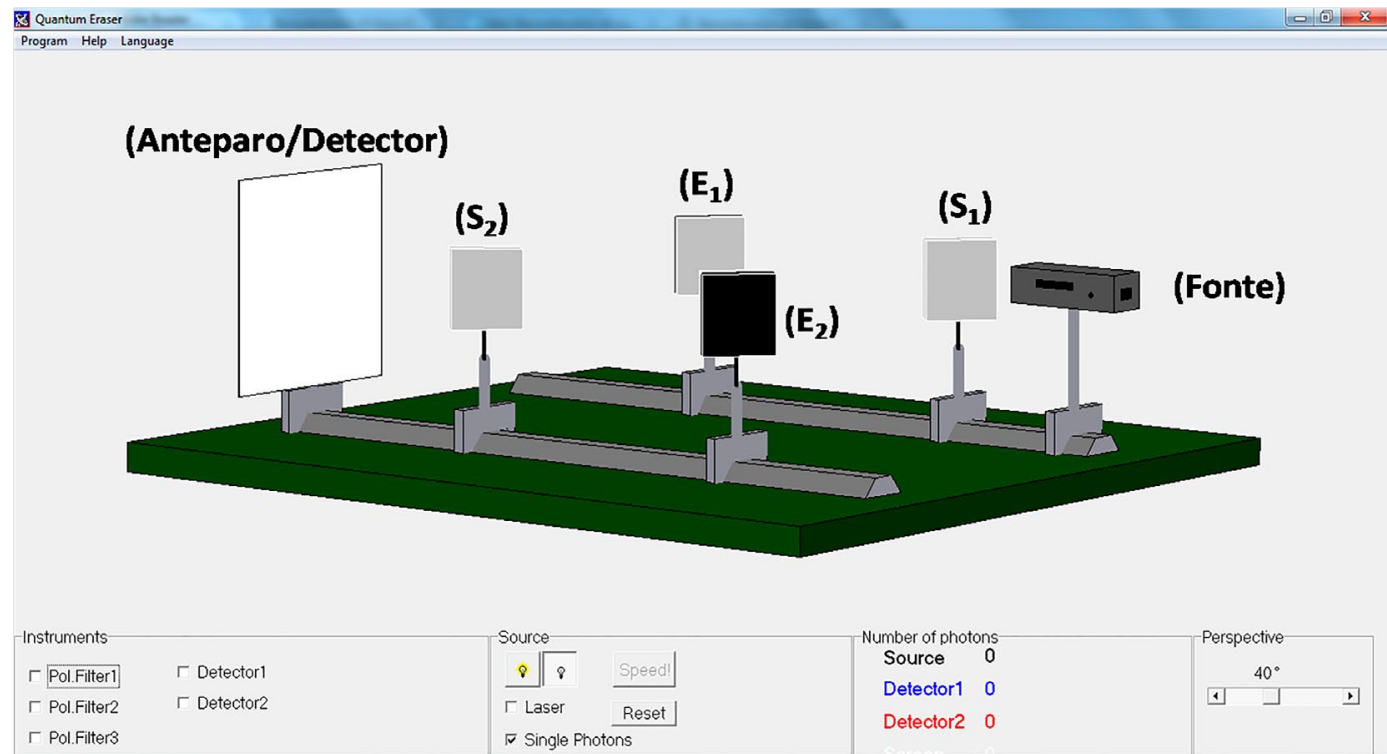

Fonte: Imagem extraída do software.

A distância entre os espelhos pode ser modificada conforme os objetivos do experimento, mas os espelhos devem estar alinhados a fim de que o ângulo de incidência dos feixes seja sempre de $45^{\circ}$. Esse software adota uma leve diferença entre os dois braços do interferômetro, ou os dois caminhos ópticos, de forma que um padrão de anéis circulares aparece no anteparo quando a fonte emite luz laser.

Foram abordadas duas configurações do experimento. O regime clássico, com a fonte que emite feixes de luz (monofotônico), e diminui a intensidade do feixe emitido, a ponto de analisar fótons individuais explicado pela TQ. Este foi subdividido em dois arranjos, com e sem a presença de um detector. 
Um dos diferenciais das atividades com os softwares é justamente a metodologia aplicada em seus roteiros. Os experimentos virtuais foram manipulados segundo a abordagem Predict-Observe-Explain - POE, definida por uma sequência composta por três etapas a serem seguidas pelos alunos. Predizer o resultado ou desdobramento de um determinado problema proposto, é o primeiro passo. Em seguida, deve-se, neste caso, simular o experimento e observar o resultado fornecido. Por fim, a terceira etapa fornece um espaço para que o estudante compare a sua previsão e a observação (viabilizada pelos softwares), explicando as possíveis diferenças (TAO; GUNSTONE, 1999).

\section{Os storyboards}

A ideia da construção dos storyboards, bem como a modelização das representações presentes, surgiram partindo de estudos anteriores (TREVISAN; SERRANO, 2014; TREVISAN; SERRANO, 2016; TREVISAN; SERRANO, 2018) nos quais verificamos resultados apontando que apenas as bancadas virtuais não forneciam representações conceituais a respeito dos possíveis comportamentos dos objetos quânticos ao longo dos setups experimentais, tanto para a dupla fenda, quanto para o IMZ.

Desta forma, com o intuito de preencher esta lacuna interpretativa e não a deixar apenas a cargo do estudante, ao tentar imaginar explicações conceituais plausíveis para justificar os padrões de interferência e não interferência formados no anteparo, decidimos elaborar ilustrações representacionais, que com traços gráficos elementares, simbolizassem de maneira acessível as concepções de cada grande grupo interpretativo, para explicar os resultados empíricos. Procuramos manter o rigor conceitual, mesmo tendo consciência de que o mundo quântico não seja idealizado desta maneira.

As ilustrações foram realizadas por modelizações baseadas nas conjecturas das quatro principais interpretações da $\mathrm{MQ}$, são elas: Corpuscular (Realista), Ondulatória (Realista), Dualista Realista e a Dualista Positivista. Essa classificação ocorre conforme a referência principal adotada para toda elaboração do material didático. Para tal, utilizamos as obras do físico e filósofo da ciência Osvaldo Frota Pessoa Junior, das quais, as mais consultadas foram de 1997, 2006 e 2008. 
Os storyboards abordam apenas o arranjo experimental da dupla fenda em todas suas configurações (elencadas na seção anterior). Optamos por não mencionar as explicações para o IMZ, para que após tal implementação fosse possível analisar se os estudantes alcançaram uma própria modelização científica a partir destas mediações externas para o IMZ e se expressaram, assim, com maior ênfase, a sua interpretação privada para os comportamentos dos objetos quânticos. Não é o foco deste trabalho tratar ou medir se a aprendizagem ocorrida é significativa sob a perspectiva Ausubeliana. No entanto, acreditamos que se o aluno, frente a uma nova situação, consegue utilizar os subçunsores modificados para resolver tal problema, esta compreensão flerta com a aprendizagem significativa (AUSUBEL, 1968).

Os storyboards seguem uma sequência para cada grupo interpretativo, e basicamente respondem quatro perguntas centrais, a saber:

- Qual é a interpretação do Estado Quântico (epistêmico ou real)?

- Como surgem as franjas claras e escuras (regiões "permitidas" ou "não")?

- Como um observador pode interferir no resultado obtido no anteparo?

- Como a interpretação encara o "problema" da não-localidade?

As imagens a seguir apresentam as ilustrações representativas acerca de cada interpretação, a fim de explicar conceitualmente, através de suas conjecturas, os resultados observados no anteparo. Expressaremos dois exemplos: o primeiro trata como a interpretação caracteriza a entidade quântica; o segundo, como o comportamento desta entidade quântica ocorre, explicando o padrão de interferência quando a fonte está em regime quântico sem a presença de um detector.

Caso 1 - A caracterização da entidade quântica e interpretação do estado quântico $\psi$ :

- Interpretação Corpuscular (Realista)

O elétron e o fóton são partículas e manifestam-se desta forma quando são detectados. 
Figura 4: Recorte do storyboard. Ilustração do objeto quântico sob o ponto de vista da Interpretação Corpuscular

Objetos quânticos:

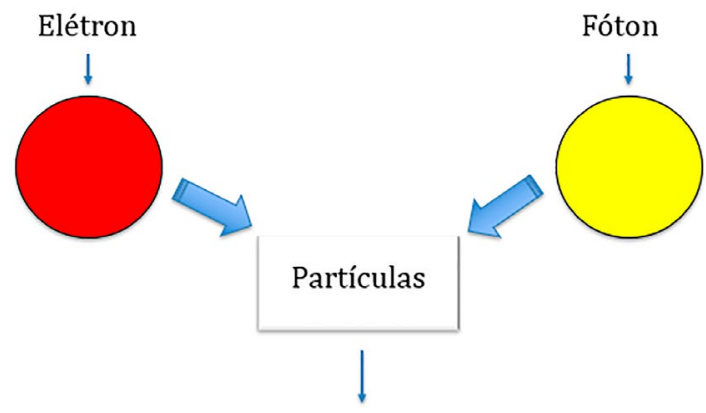

E manifestam-se desta forma quando são detectados

Fonte: A pesquisa.

E a interpretação para o estado quântico:

$|\psi\rangle \rightarrow$ Epistêmico.

$|\psi\rangle \rightarrow$ Incompleto (não se aplica a um objeto individual).

\section{- Interpretação Ondulatória (Realista)}

O elétron e o fóton são ondas espalhadas e quando detectados tornam-se um pacote de onda estreito.

Figura 5: Recorte do storyboard. Ilustração do objeto quântico sob o ponto de vista da Interpretação Ondulatória Objetos quânticos:

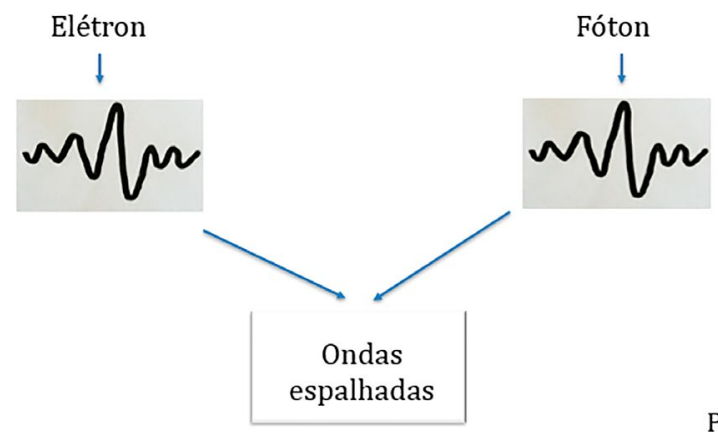

Pacote de onda estreito

Fonte: A pesquisa. 
E a interpretação para o estado quântico:

$|\psi\rangle \rightarrow$ Real.

$|\psi\rangle \rightarrow$ Completo.

- Interpretação Dualista Realista

O elétron e o fóton são partículas com ondas associadas (pilotos) e somente a porção corpuscular é detectada no anteparo.

Figura 6: Recorte do storyboard. llustração do objeto quântico sob o ponto de vista da Interpretação Dualista Realista.

Objetos quânticos:
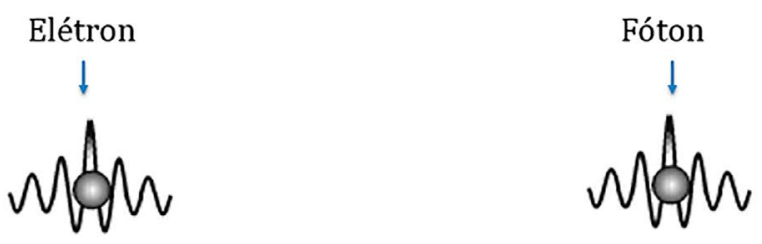

Partículas com ondas associadas

Fonte: A pesquisa.

E a interpretação para o estado quântico:

$|\psi\rangle \rightarrow$ Real.

$|\psi\rangle \rightarrow$ Incompleto (variáveis ocultas).

- Interpretação Dualista Positivista

O elétron e o fóton podem ser ondas ou partículas, esta interpretação atribui realidade apenas ao que é observado. Quando detectadas, as entidades quânticas se manifestam como corpúsculos. 
Figura 7: Recorte do storyboard. Ilustração do objeto quântico sob o ponto de vista da Interpretação Dualista Realista

Objetos quânticos:

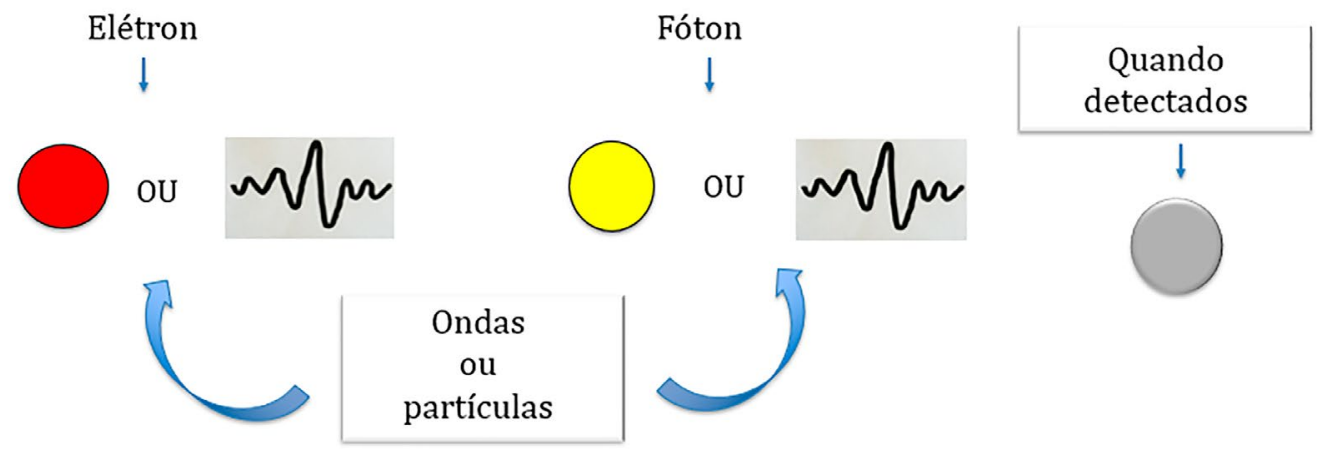

Atribui realidade apenas ao que é observado.

Fonte: A pesquisa.

E a interpretação para o estado quântico:

$|\psi\rangle \rightarrow$ Epistêmico.

$|\psi\rangle \rightarrow$ Completo.

Caso 2 - A formação do padrão de interferência no anteparo, na ausência de um detector:

\section{- Interpretação Corpuscular (Realista)}

Quando uma partícula interage com um cristal de comprimento $l$, o momento da partícula pode alterar em múltiplos de $h / l$, ou seja, as fendas transfeririam momento de forma quantizada para o elétron, ocasionando o padrão de interferência. Tal explicação só serviria para arranjos experimentais com anteparos rígidos, e não para outros tipos de experimentos, como o biprisma eletrônico (PESSOA JR, 2006). 
Figura 8: Recorte do storyboard. llustração da ocorrência do padrão de interferência sob o ponto de vista da Interpretação Corpuscular

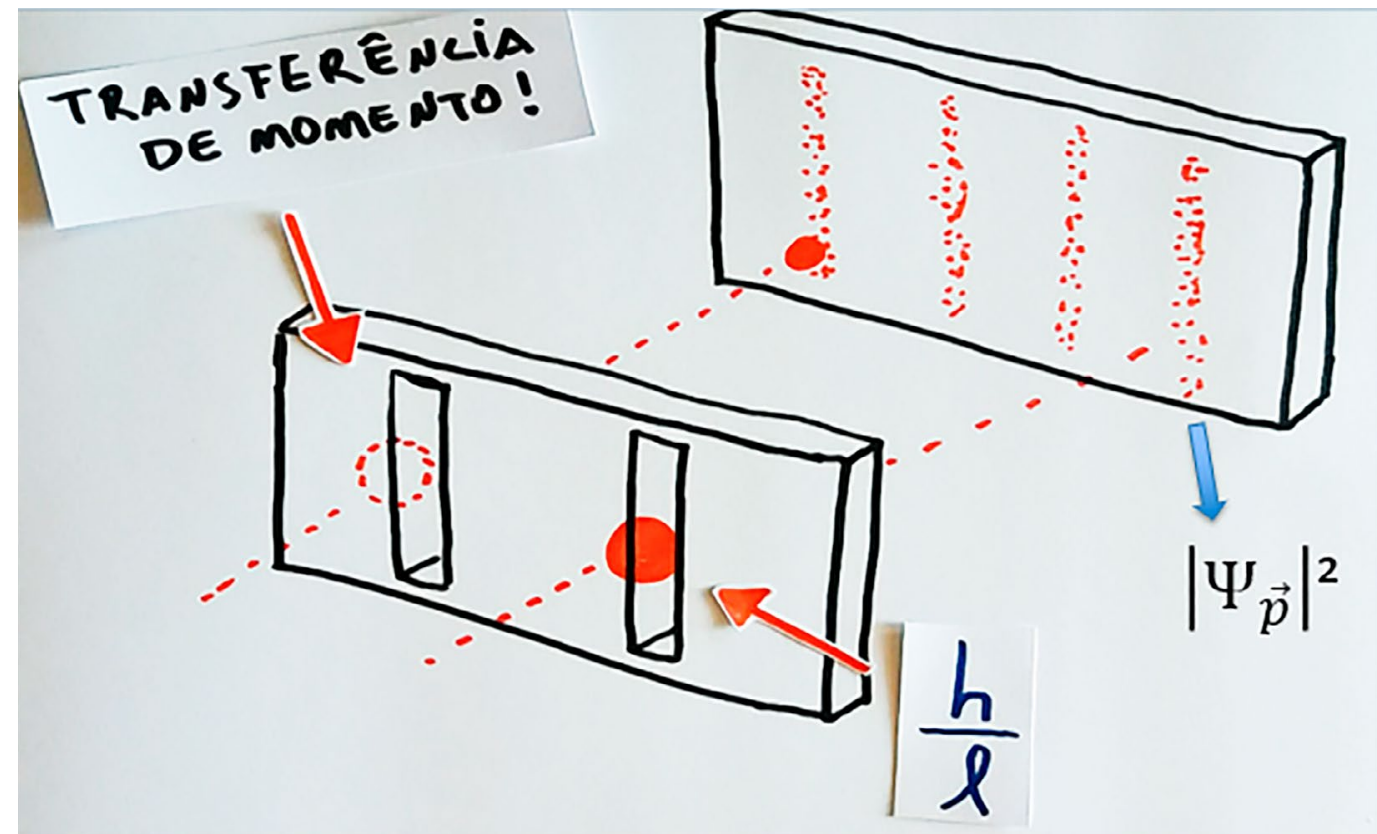

Fonte: A pesquisa.

Ressaltamos que esta imagem não é a única utilizada para explicar as ideias da interpretação, não apresentaremos as demais, que complementam a sequência, devido à preocupação com a extensão deste trabalho.

\section{- Interpretação Ondulatória (Realista)}

Após atravessar as fendas, o pacote de onda associada ao elétron parte-se em dois, o que pode ser expresso por uma função de onda do tipo $\psi_{A}+\psi_{B}$. As franjas claras e escuras acontecem devido à diferença de fase das frentes de ondas associadas ao elétron, originadas após passarem pelas fendas. 
Figura 9: Recorte do storyboard. llustração da formação do padrão de interferência sob o ponto de vista da Interpretação Ondulatória

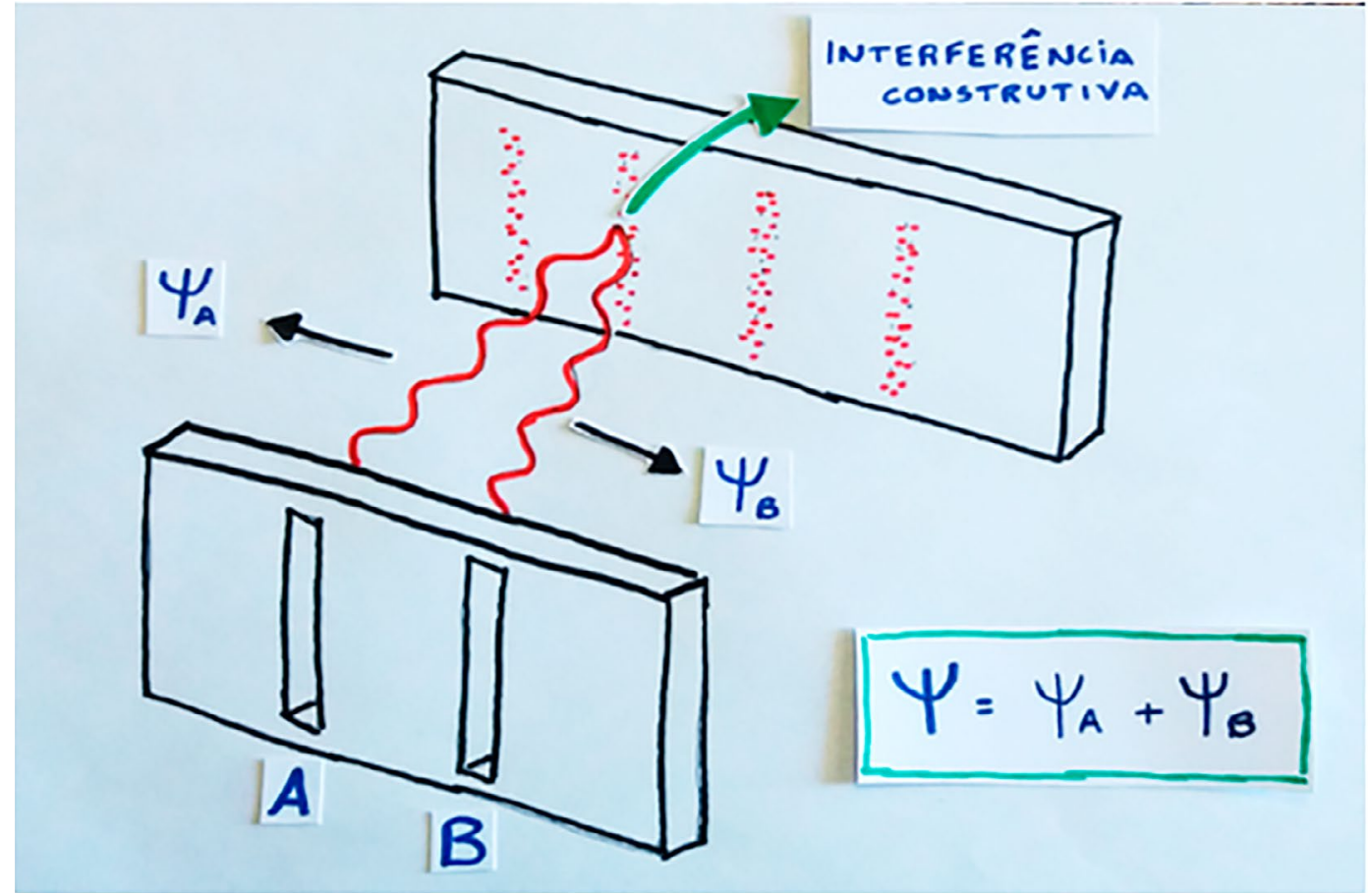

Fonte: A pesquisa.

Em outras situações, as ondas foram representadas em formato circular, uma outra possiblidade de representar o objeto quântico com ontologia ondulatória. Ambas podem sinalizar a mesma intenção conceitual ilustrativa.

\section{- Interpretação Dualista Realista}

O objeto quântico se divide em duas partes: uma partícula com trajetória bem definida (mas desconhecida) e uma onda associada. As ondas passam pelas duas fendas, mas a partícula em apenas uma, seguindo por caminhos possíveis, sendo estes os pontos nos quais as suas "ondas piloto" interferem construtivamente. 
Figura 10: Recorte do storyboard. Ilustração da ocorrência do padrão de interferência sob o ponto de vista da Interpretação Dualista Realista

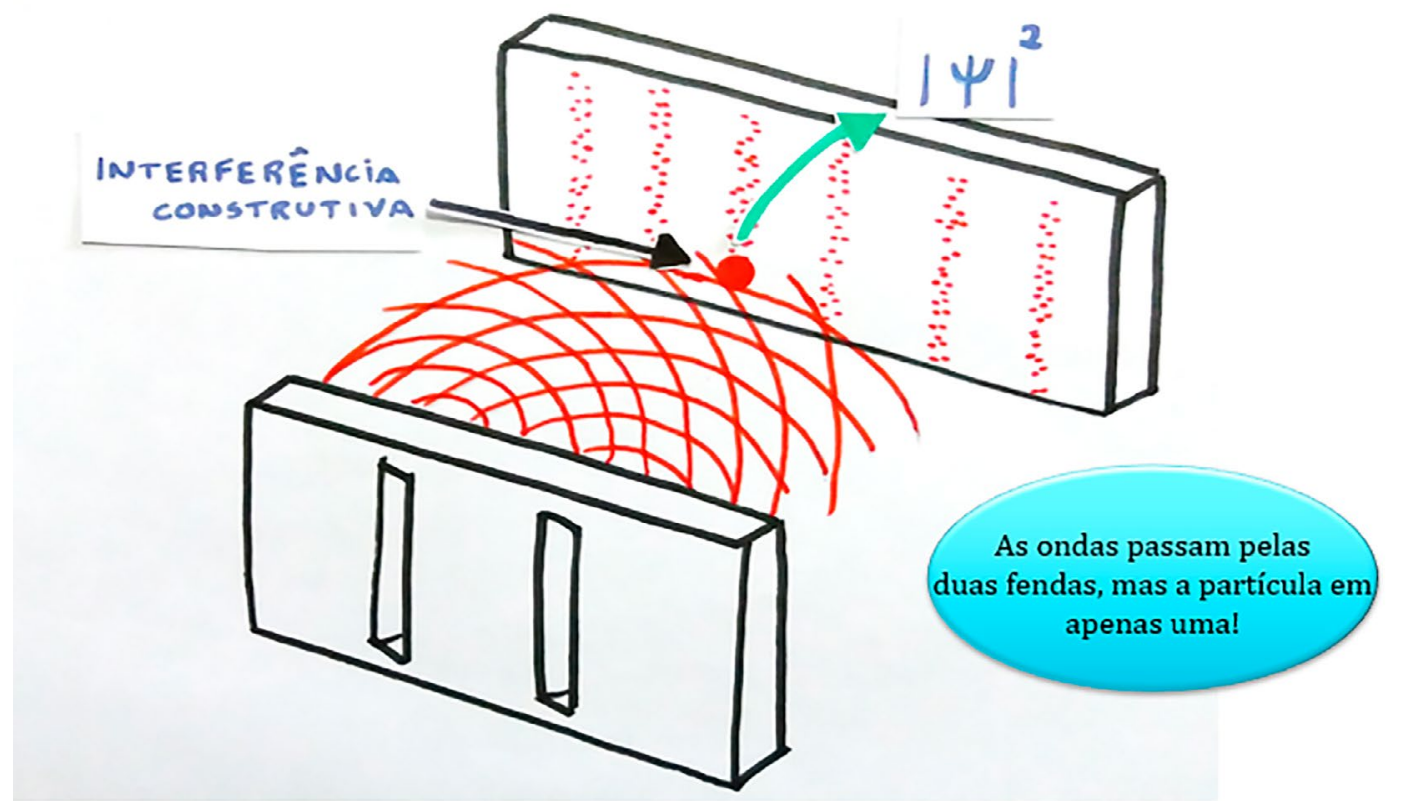

Fonte: A pesquisa.

Em regiões onde as ondas interferem destrutivamente, não há partículas.

\section{- Interpretação Dualista Positivista}

Em conformidade com o Princípio da Complementaridade de Bohr enunciado em 1927, um experimento quântico pode ser representado ou em um quadro corpuscular ou em um quadro ondulatório, nunca em ambos ao mesmo tempo. Esses aspectos da experiência seriam mutuamente excludentes.

Nesta configuração experimental sem a presença de um detector, ocorre o padrão de interferência, portanto, o comportamento do objeto quântico é ondulatório. Logo, o elétron ou fóton, em questão, combina-se consigo mesmo construtivamente nas regiões de detecção e destrutivamente nas regiões onde o fóton não é detectado. 
Figura 11: Recorte do storyboard. llustração da ocorrência do padrão de interferência sob ângulo da Interpretação Dualista Positivista

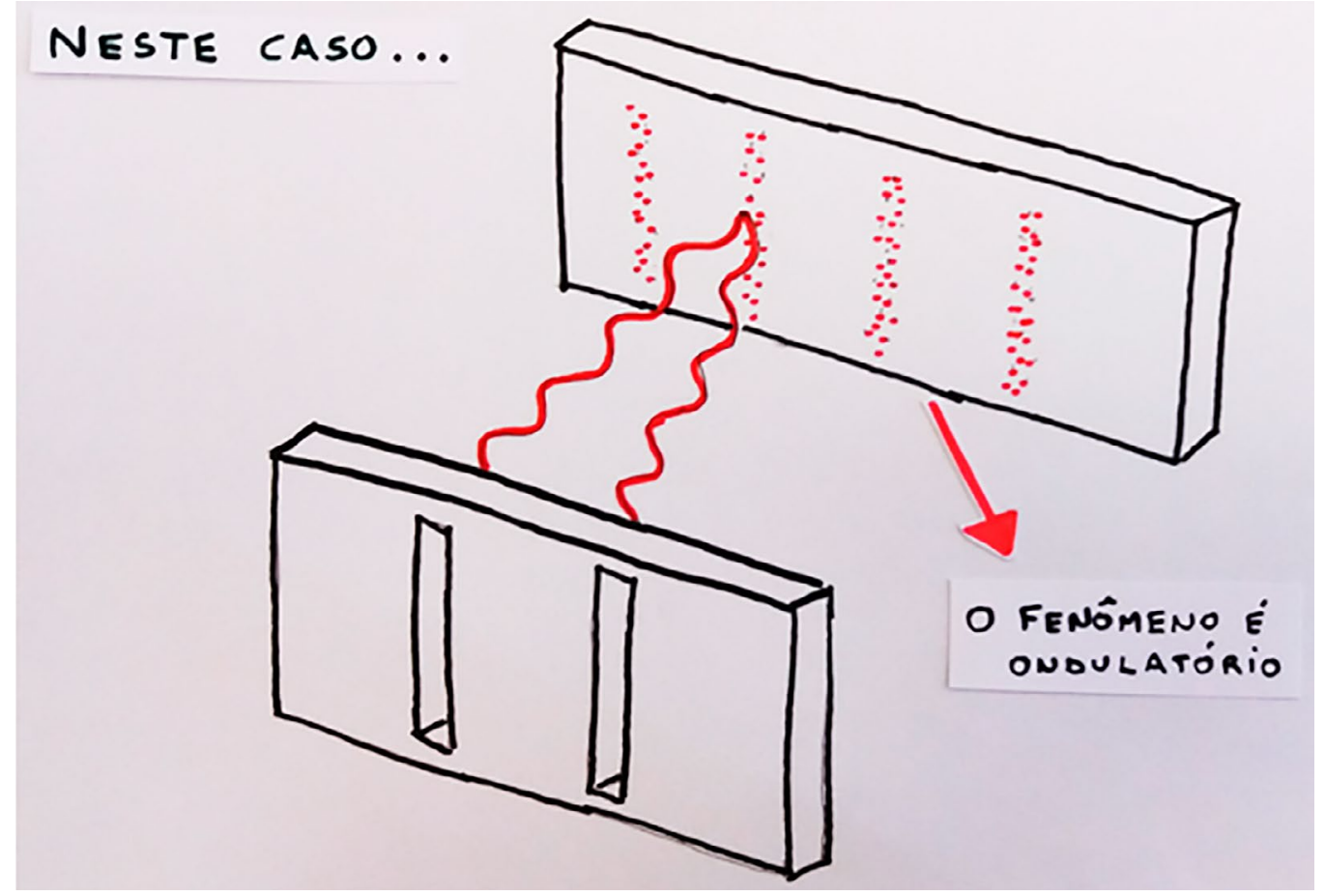

Fonte: A pesquisa.

O fenômeno em questão é ondulatório e não corpuscular, não se pode inferir a trajetória do objeto quântico detectado. Mudando o arranjo experimental com o acréscimo de um detector/observador, o padrão de interferência não é formado, consequentemente, o elétron/fóton seria interpretado com comportamento corpuscular.

Na sequência, apresentaremos o problema norteador de pesquisa desta investigação e o delineamento metodológico adotado para resolvê-lo.

\section{Problema de pesquisa e delineamento metodológico}

Nossa proposta de investigação busca analisar como o uso combinado das bancadas virtuais com os storyboards podem promover a compreensão conceitual do licenciando em Física em de tópicos fundamentais da MQ. Verificamos, desse modo, a probabilidade do seu estabelecimento em uma corrente interpretativa. 
Compatível com esse cenário, despontamos pergunta de pesquisa norteadora deste estudo:

Quais são as potencialidades da utilização de bancadas virtuais e storyboards com ilustrações de cunho interpretativo no ensino e aprendizagem da dualidade onda-partícula?

Com o propósito de responder esta pergunta, os delineamentos metodológicos adotados convergem para caminhos que tornam capaz a identificação das representações mentais e drivers presentes na modelização realizada pelos estudantes para interpretar os resultados observados na dupla fenda e no IMZ. Analisa-se a contribuição e aporte conceitual das ferramentas de processamento externo de informação empregadas na proposta didática.

Nesta investigação, o ser humano é o eixo basilar do estudo, sobretudo pela intenção de analisar o funcionamento da estrutura cognitiva do estudante, se os mecanismos externos de mediação, empregados nas instruções didáticas, promoveram a inclinação à uma determinada postura interpretativa. Desse modo, utilizamos métodos qualitativos para levantar e analisar os dados da investigação (ERICKSON, 1986).

As instruções didáticas foram desenvolvidas ao longo de duas disciplinas introdutórias de MQ, nos cursos de Licenciatura em Física, de duas instituições de ensino superior, somando 17 estudantes. A tabela a seguir resume o universo da pesquisa.

Tabela 1: Universo da pesquisa.

\begin{tabular}{l|l|c|c}
\hline \multicolumn{1}{c|}{ IES } & \multicolumn{1}{|c|}{ Disciplina } & Número de alunos & Período \\
\hline IES “A” & Mecânica Quântica & 8 & $2018 / 01$ \\
IES “B” & Física Moderna e Contemporânea I & 9 & $2018 / 02$ \\
\hline
\end{tabular}

Fonte: A pesquisa.

A sequência de ações didáticas que configuram a implementação da proposta, obedece a uma segmentação composta por sete etapas, brevemente descritas a seguir:

Etapa I - Teste I: Inicialmente, o teste I foi elaborado e corroborado pelos autores, para em seguida ser disponibilizado para a resolução dos licenciandos. Este primeiro questionário é uma sondagem conceitual que antecede os estudos teóricos com os experimentos virtuais e storyboards. Este teste é constituído por 9 questões, das quais 6 são abertas e 3 são fechadas. A intenção deste instrumento é 
justamente examinar as concepções dos estudantes que possam conduzi-los a uma interpretação privada para o fenômeno da dualidade onda-partícula antes mesmo de qualquer instrução didática.

Etapa II - Atividade com softwares computacionais: Seguindo um plano de atividades construído alicerçado na premissa P.O.E. (predict-observe-explain) (TAO; GUNSTONE, 1999), esta etapa é composta pela interação dos licenciandos com os dois experimentos virtuais propostos: o software A - Interferômetro Virtual de Mach-Zehnder e o software B - Fenda Dupla de Young.

Etapa III - Teste II: Neste segmento, um segundo teste, com as mesmas questões do teste anterior, foi respondido pelos licenciandos. O intuito da ferramenta é apurar, após a iteração com os simuladores virtuais, as possíveis mudanças das concepções dos estudantes a respeito da dualidade onda-partícula.

Etapa IV - Entrevista dos Testes I e II: Este momento, engendrado conforme o protocolo Report Aloud (TREVISAN et. al. 2019), é caracterizado por entrevistas, nas quais cada aluno, individualmente, é orientado a explicar as suas justificativas para as respostas dos testes I e II.

Etapa V - Aulas mediadas pelos Storyboards: Este momento é caracterizado pelas instruções didáticas mediadas essencialmente pelos storyboards. As quatro principais interpretações da MQ foram estudadas a partir das suas compreensões e postulados para os resultados observados nas diferentes possibilidades de configurações experimentais do arranjo da dupla fenda. Esta sequência pedagógica segue as ideias de Bunge (1974) para os modelos científicos, à vista disso, representamos os objetos-modelos, buscando relacioná-los com o modelo teórico que estabelece o seu comportamento, isso tudo sob a abrangência de uma teoria mais abrangente.

Etapa VI - Teste III: Implementação e resolução do Teste III, na semana seguinte a conclusão das instruções didáticas. O teste é composto por um total de 12 questões abertas e fechadas, semelhantes as contidas no Teste II.

Etapa VII - Entrevista do Teste III: Este segmento do estudo é semelhante ao desenvolvido na etapa IV. O que os difere são as suas pautas. Aqui, o dialogo estabelecido de acordo com o protocolo Report Aloud (TREVISAN, et. al. 2019), direciona-se para as justificativas dos licenciandos às suas respostas presentes no teste III. 
Figura 12: Síntese das etapas da investigação
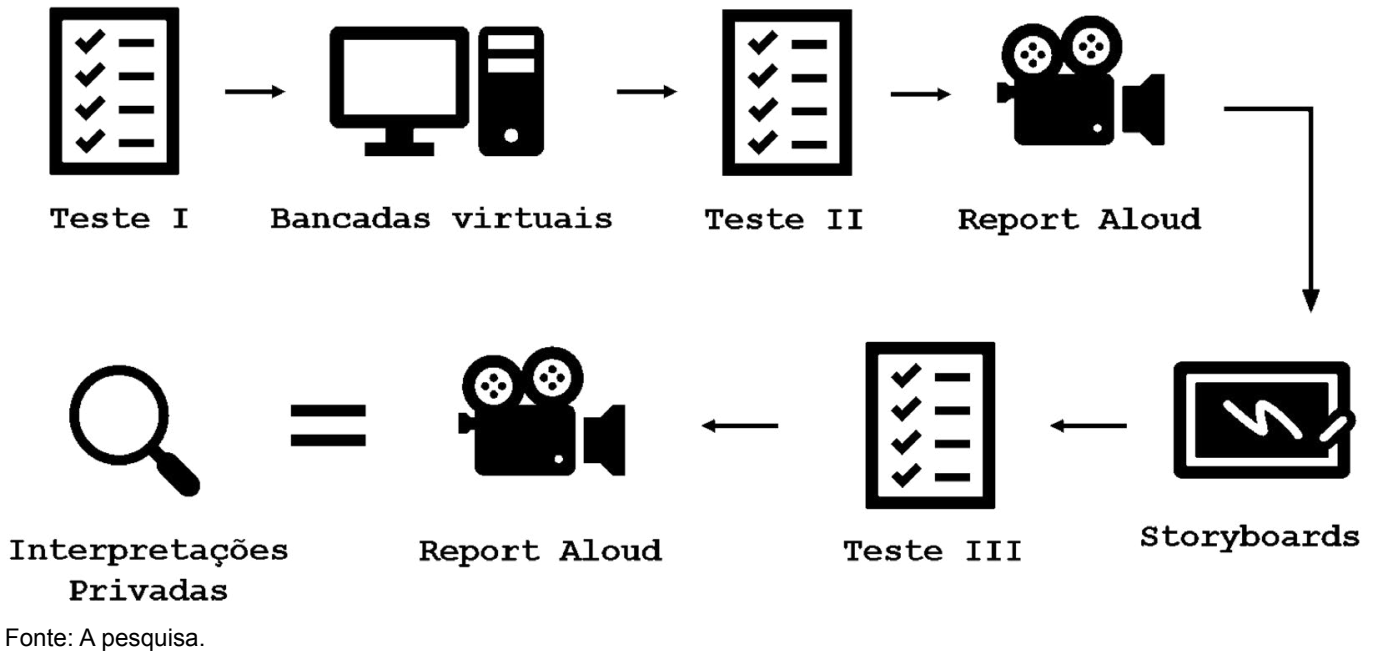

A seguir, são apresentados os resultados do estudo, juntamente com suas discussões pertinentes ao âmbito das interpretações expressadas pelos alunos.

\section{Resultados e discussões}

As análises voltam-se ao balanço das potencialidades dos mecanismos externos de mediação na promoção da compreensão conceitual do fenômeno da dualidade onda-partícula presente nos experimentos virtuais da dupla fenda e do IMZ. Ou seja, buscamos verificar se os acadêmicos após as instruções didáticas, apresentaram indícios em inclinar-se a uma determinada corrente interpretativa, com base na Análise Textual Discursiva (MORAES; GALIAZZI, 2007) e Análise Gestual Descritiva (MONAGHAN; CLEMENT, 1999; STEPHENS; CLEMENT, 2010). Portanto, foram examinados os registros presentes nos instrumentos de produção de dados: os questionários denominados testes I, II e II, os roteiros para condução de atividades com os softwares, imagens e áudios de vídeo das entrevistas.

Analisando as explicações externalizadas pelos licenciandos, pode-se observar a presença dos quatro grupos de interpretações. Isso quer dizer que as bancadas virtuais, juntamente com os storybords, proporcionaram subsídios representacionais e conceituais de modo que os estudantes assimilassem as conjecturas que mais lhe agradavam quando no momento de justificar as respostas presentes no anteparo. 
Em termos estatísticos, a Fig. 13, a seguir, exibe a distribuição das interpretações admitidas pelos estudantes, ainda que de forma incipiente.

Figura 13: Relação numérica das interpretações adotadas.

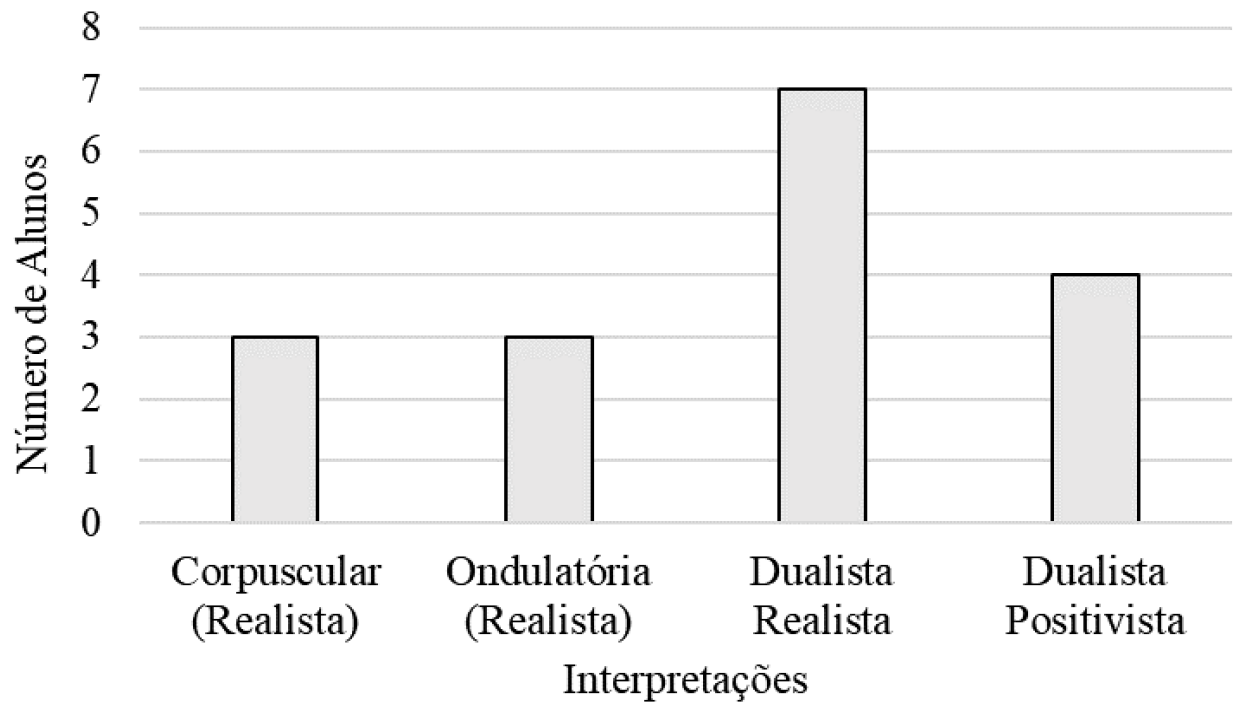

Fonte: A pesquisa.

O gráfico nos mostra que a interpretação dualista realista obteve maior destaque nas explicações formuladas pelos licenciandos no momento de justificar suas respostas nos testes. Analisando a postura interpretativa dos alunos, confirmamos que elementos conceituais das quatro correntes interpretativas apareceram nas explicações dos resultados dos experimentos. Isto nos diz que as bancadas virtuais juntamente com os storybords forneceram possibilidades de diferentes formas para analisar ontologicamente e epistemologicamente um mesmo resultado, previsto pelo formalismo da MQ, consolidado e indiscutível pela comunidade científica.

As bancadas virtuais foram mais eficientes no auxílio das previsões dos resultados a serem formados no anteparo. Quase que a totalidade dos estudantes mencionou os softwares quando solicitado para relatar a lembrança principal que o fez optar por tal resultado nos testes. Já os storybords contribuíram para a formação das interpretações individuais que buscam explicar como o objeto quântico comportou-se no setup experimental, para que tal resultado surgisse no anteparo 
de visualização. Procurando, assim, justificativas teóricas para a ocorrência ou não do padrão de interferência.

Como os storybords só apresentavam ilustrações representativas para o experimento de dupla fenda, presumimos que os licenciandos as utilizassem como referência na construção da compreensão dos resultados exibidos no IMZ, realizando, portanto, uma modelização científica espontânea. De fato, a maioria dos acadêmicos transladaram os princípios das interpretações, direcionados à dupla fenda, para o IMZ.

As situações nas quais os storyboards foram mencionados em maior frequência como mecanismo externo de mediação responsável pelo auxílio na elaboração da resposta, foram nos regimes quânticos da dupla fenda e do IMZ, ambos sem a presença de um detector/observador. Devido à preocupação com a extensão deste trabalho, apresentaremos a seguir um caso formado pelos exemplos de explicações dos alunos que se inclinaram à interpretação Dualista Realista ao explicar o resultado de interferência na dupla fenda em regime monoeletrônico sem a presença de um detector. Optamos pela escolha desta situação por ser o caso no qual a linguagem verbal e não verbal dos licenciandos espelham-se com maior rigor nas ilustrações representativas modelizadas nos storybords.

Diante deste contexto, temos os seguintes exemplos:

Aluno 1: Imagino uma bolinha saindo da fonte (Fig. 14 - I), seguindo uma trajetória (Fig 1 - II), que seria definida pela onda (associada), é claro que nós não vamos ver a onda.

Pesquisador: E o elétron chega nas fendas, o que acontece?

Aluno 1: A divisão da onda (Fig. 14 - III), causando a interferência, como se fosse uma onda na água [...] A partícula sempre segue a interferência construtiva das ondas.

Figura 14: (I) Representação de uma esfera. (II) Mão direita representando a possível trajetória do elétron. (III) Duas frentes de ondas após atravessarem as fendas

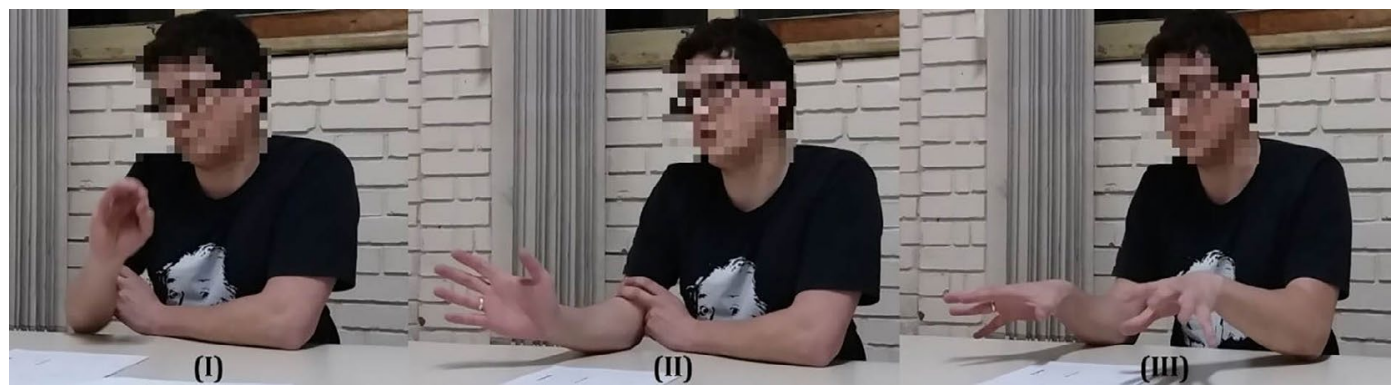

Fonte: A pesquisa. 
A componente corpuscular do elétron é indicada na forma esférica e estática, concomitantemente a sua menção no diálogo. A onda associada, também é ilustrada gestualmente no exato instante em que é citada verbalmente, neste caso, a componente ondulatória ganha dinamismo, representando o movimento do objeto quântico. A gesticulação realizada pelo Aluno 1 concorda com o seu discurso verbal, reforçando a evidência da representação mental utilizada na compreensão do resultado de interferência no anteparo. À vista disso, ressaltamos a conveniência da Análise Gestual Descritiva (MONAGHAN; CLEMENT, 1999; STEPHENS; CLEMENT, 2010), na qual trata a estreita relação entre as imagens mentais e os gestos dos estudantes, considerando estas como indícios concretos de processos cognitivos desenvolvidos pelos sujeitos quando indagados sobre determinadas situações/problemas.

Corroborando com a mesma linha de raciocínio, o Aluno 12 assegura imaginar o elétron como uma partícula com onda associada, sendo que o padrão de interferência surge, pois, “a onda se divide entre as duas fendas e o elétron (partícula) passa por uma só. Essa divisão (das ondas) cria as interferências (Fig. 15 - I), onde o elétron não é permitido" (Aluno 12). Essa representação e comportamento do elétron também é expressada pelo Aluno 3, "o elétron segue as interferências construtivas das ondas (Fig. 15 - II)".

Figura 15: (I) Duas mãos entrelaçadas representando a superposição das ondas. (II) Movimento oscilatório com uma das mãos, indicando o caminho do elétron
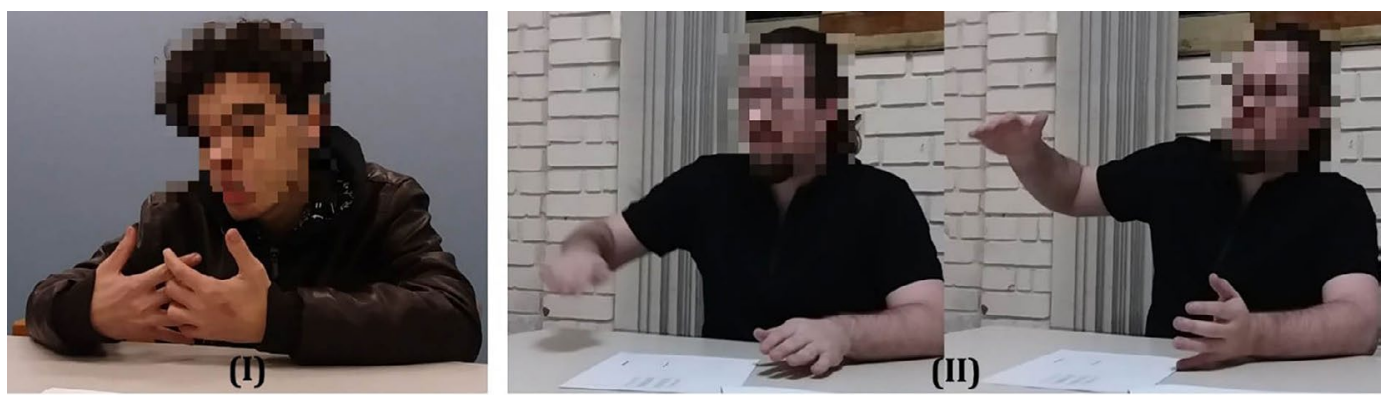

Fonte: A pesquisa.

Em ambas as imagens, os gestos realizados estabelecem uma relação direta com a linguagem verbal dos estudantes, esclarecendo a externalização das representações mentais empregadas em seu raciocínio. Na Fig. 15-1 percebe-se a interferência projetada pelo aluno, na qual aparenta ser a soma de ondas circulares em movimento frontal. Já na Fig. 15-2, o Aluno 3 representa o movimento oscilatório 
para o elétron, percorrendo os pontos de máximo e mínimo da interferência das ondas, assemelhando-se ao movimento senoidal, oferecendo outros detalhes de como imagina o movimento do elétron e a interferência ondulatória. Essas caracterizações reveladas pelos gestos, por exemplo, em diversas situações não conseguem ser acessadas apenas com o discurso verbal. Acentua-se, a importância de que estas minúcias conceituais são de grande valia na análise das representações mentais e drivers utilizados pelos licenciandos na resolução dos problemas.

O Aluno 4 também imagina o objeto quântico com ondas circulares associadas, que "guiam" a partícula (Fig. 16 - I) em seguida faz uma analogia ao afirmar que o compara com "uma galáxia em miniatura, um monte de poeirinha" (Fig. 16 - III) (Aluno 4). No entanto, difere a sua explicação em termos do comportamento do elétron, na sua concepção, tanto a onda associada quanto a partícula se dividem nas duas fendas.

Figura 16: (I) Sequência de fotos para representar o elétron: indicador e polegar para representar um corpo pontual e em seguida os dois indicadores oscilando para representar a onda. (II) As duas mãos oscilando esfericamente para representar a analogia da galáxia
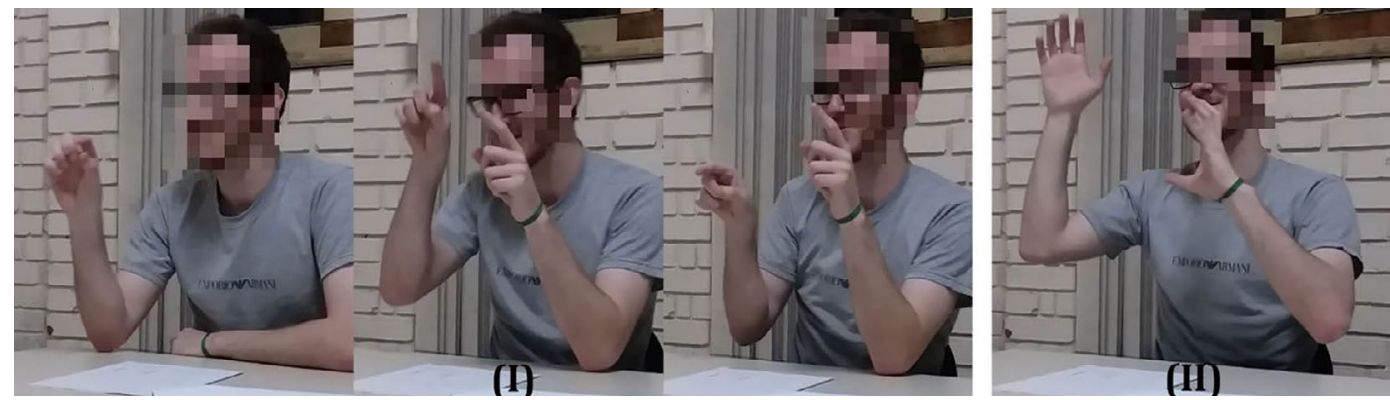

Fonte: A pesquisa.

Os gestos realizados são importantes auxiliares na identificação das representações mentais do Aluno 4, o mesmo considera o elétron composto por um corpo pontual, possível de ser observado com a primeira imagem da Fig. 16-I, sendo que a sequência da representação descreve a componente ondulatória do objeto quântico, com o indicador da mão direita em movimento vertical formando semicírculos em frente ao indicador da mão esquerda, estático, representando o corpo pontual. Na Fig. 16-II ocorre a imitação da metáfora utilizada, com as duas mãos espalmadas aparentemente envolvendo um corpo central, indicando a sua noção acerca do elétron. 
Diante destas explicações, percebe-se que as representações mentais utilizadas pelos estudantes se assemelham às ilustrações dos storybords s, e, desta forma, podemos inferir a influência desta ferramenta no complemento as bancadas virtuais, procurando preencher as lacunas interpretativas não abarcadas explicitamente pelos softwares.

Apesar desse resultado positivo, observamos que para a configuração experimental do IMZ em regime quântico, com a presença de um detector, em torno de $60 \%$ das explicações dos estudantes apresentaram-se de forma desconexa Isto é, os conceitos empregados não davam conta de justificar o resultado da não formação de interferência, ainda que a resposta no anteparo tenha sido prevista corretamente por quase todos os alunos.

\section{Considerações finais}

neste trabalho, verificamos como uma proposta didática mediada por bancadas virtuais e storyboards podem contribuir para que os estudantes de Física - Licenciatura construam interpretações privadas acerca da MQ, ainda que de forma incipiente. Para tanto, realizou-se uma articulação teórico-metodológica inovadora na investigação em Ensino de Física, caracterizada pela Teoria da mediação Cognitiva em conjunto com a Modelização Científica Bungeana, como aporte epistemológico norteador na tomada de decisões ao longo de todo processo instrucional, e pela fundamentação metodológica no movimento da análise em que o Report Aloud é responsável pela condução e execução da análise gestual discursiva juntamente com a análise verbal.

Cabe ressaltar que os momentos de diálogo proporcionados pela técnica Report AIloud possibilitam ao estudante externalizar de forma verbal e gestual a sua compreensão acerca de conceitos científicos específicos. Em múltiplas investigações em ensino de ciências esse entendimento exteriorizado é utilizado em favor do professor, caracterizando-se como fator potencializador no ensejo de planejamento e desenvolvimento de situações didáticas, com o propósito de ensino de determinados conteúdos em sala de aula. Ademais, a análise gestual permite extrair evidências implícitas ao discurso do estudante. 
À luz dos resultados desta pesquisa e levando em consideração os apontamentos de estudos anteriores, acreditamos que seja importante o desenvolvimento de ações pedagógicas que não se confinem apenas a abordagem tradicional da $\mathrm{MQ}$, carregada de procedimentos algébricos, já que nestes cursos introdutórios os estudantes em sua grande maioria generalizam suas concepções intuitivas da física clássica para os sistemas quânticos, podendo leva-los a uma aprendizagem deficitária.

Em outros termos, compreendemos que se deve desenvolver e aprimorar a estruturação de metodologias e estratégias didáticas, as quais dão ênfase à compreensão conceitual e interpretativa de fenômenos quânticos, sobretudo em cursos de formação de docentes, desenvolvendo as habilidades matemáticas fundamentais necessárias para a construção do formalismo quântico. Consideramos, desse modo, capital a equidade no decurso do ensino de conteúdos introdutórias de MQ, quando uma parte significativa dos cursos enfatizam apenas os algoritmos de resolução, em vez de incluir a interpretação conceitual dos fenômenos em proporções semelhantes.

\section{Agradecimentos}

À Coordenação de Aperfeiçoamento de Pessoal de Nível Superior (CAPES) e à Fundação de Amparo à Pesquisa do Estado do Rio Grande do Sul (FAPERGS) pelo apoio no subsídio desta pesquisa.

\section{Virtual benches and storyboards with representative microscopic illustrations as resources in the study of Quantum Mechanics}

\section{Abstract}

This article aims to analyze how the combined use of virtual benches and storyboards can promote the conceptual understanding of undergraduate physics about the phenomenon of quantum entity wave-particle duality in the experimental arrangements of double slit and IMZ. Thus, we verify the possibility of its establishment in an interpretative current of QM. The conduct of this investigation converges to the identification of students' private interpretation, after didactic actions mediated by external mechanisms of information processing. To do so, we adopted the harmonization of two theoretical frameworks, the Cognitive Mediation Theory (TMC), due to its approach related to hypercultural mediation, and the Scientific Modeling of Mario Bunge, due to his perception about the construction of reasoning knowledge through the interpretation of the reality. The results were obtained after the analysis performed under the pretest, posttest and 
analysis of the descriptive gestures obtained from the video images recorded during the posttest interviews. We found that the didactic instructions provided possibilities to the undergraduates to analyze ontologically and epistemologically, in different ways, the same empirical result, predicted by the QM formalism. We also identified the predominance of a realistic dualist stance in student's interpretation.

Keywords: Physics Education. Quantum Mechanics. Virtual Experiments. Storyboards. Report Aloud.

\section{Notas}

1 Por ora, o leitor pode considerar que "drivers" são apresentados pela Teoria da Mediação Cognitiva como "máquinas virtuais" internas, armazenando informações através da sua interação com mecanismos externos, os drivers são acessados pelo cérebro.

2 Disponível em http://www.didaktik.physik.unimuenchen.de/archiv/inhalt_materialien/doppelspalt/index. html. Acesso em: 23 ago. 2019.

3 Disponível em http://www.physik.uni-muenchen.de/didaktik/Computer/interfer/interfere.html. Acesso em: 29 maio 2019.

\section{Referências}

aKARSU, Bayram. Einstein's Redundant Triumph "Quantum Physics": An extensive Study of Teaching /Learning Quantum Mechanics in College. Latin-American Journal of Physics Education. Latin American Journal of Physics Education, v. 4, n. 2, p. 273-285, 2010.

AUSUBEL, D. P. Educational psychology: a cognitive view. New York: Holt, Rinehart and Winston. 1968.

AYENE, M.; KRIEK, J.; DAMTIE, B. Wave-particle duality and uncertainty principle: Phenomenographic categories of description of tertiary physics students" depictions. Physical Review Special Topics-Physics Education Research, v. 7, n. 2, p. 020113, 2011.

BAILY, C.; FINKELSTEIN, N. D. Teaching and understanding of quantum interpretations in modern physics courses. Physical Review Special Topics-Physics Education Research, v.6, n. 1, p. 010101, 2010.

BAILY, C; FINKELSTEIN, N. D. Teaching quantum interpretations: Revisiting the goals and practices of introductory quantum physics courses. Physical Review Special Topics-Physics Education Research, v. 11, n. 2, p. 020124, 2015.

BUNGE, M. Filosofia da Física: edições 70, Lisboa, Portugal, 1973.

BUNGE, M. Teoria e Realidade: editora Perspectiva S.A., São Paulo, 1974.

CHEONG, Y. K.; SONG, J. Different levels of the meaning of wave-particle duality and a suspensive perspective on the interpretation of Quantum Theory, Science \& Education, Publicação Online, Ago. 2013. DOI 10.1007/s11191-013-9633-2.

CLEMENT, J. J.; STEPHENS, A. L. Documenting the use of expert scientific reasoning process by high school physics students. Physics Education Research, v. 6, n. 2, p. 20122-1-20122-15, 2010 . 
DOERR, H.M. Experiment, Simulation and Analysis: An integrated Instructional Approach to the Concept of Force. International Journal of Science Education, v. 19, n. 3, p. 265-282, 1997.

ERICKSON, F. Qualitative methods in research on teaching. In: Wittrock, M.C. (Ed.). Handbook of research on teaching. New York: Macmillan Publishing. p. 119-161. 1986.

FEYNMAN, R.P.; LEIGHTON, R.B.; SANDS, M. Lições de Física - The Feynman lecture on Physics. Porto Alegre: Bookman, v.3, 2008.

FISCHLER, H., LICHTFELDT, M. Modern physics and students' conceptions. International Journal of Science Education, London, v. 14, n. 2, p. 181-190, Apr./June 1992.

IRESON, G. The quantum understanding of pre-university physics students, Physics Education. v. 35, n. $1,2000$.

KOHNLE, A. Based interactive simulations to support quantum mechanics learning and teaching. Teaching/Learning Physics: Integrating Research into Practice, 2015.

LMU: Ludwig Maximiliams UniversitäT München. Facuklty of Physics: Chair of Physics Education. Disponível em: <http://www.physik.uni-muenchen.de/didaktik/Computer/interfer/interfere. html>. Acesso em: 29 maio 2019.

LMU: Ludwig Maximiliams UniversitäT München. Facuklty of Physics: Chair of Physics Education. Disponível em: <http://www.didaktik.physik.unimuenchen.de/archiv/inhalt_materialien/ doppelspalt/index.html>. Acesso em: 23 ago. 2019.

MALGIERI, M.; ONORATO, P.; DE AMBROSIS, A. Test on the effectiveness of the sum over paths approach in favoring the construction of an integrated knowledge of quantum physics in high school. Physical Review Physics Education Research. v. 13, n. 1, 2017.

MARIES, A.; SAYER, R.; SINGH, C. Effectiveness of interactive tutorials in promoting "whichpath" information reasoning in advanced quantum mechanics. Physical Review Physics Education Research, v. 13, n. 2, p. 020115, 2017.

MARSHMAN, E; SINGH, C. Interactive tutorial to improve student understanding of single photon experiments involving a Mach-Zehnder interferometer. European Journal of Physics, v. 37, n. 2, p. $024001,2016$.

MONAGHAN, J. M.; CLEMENT, J. J. Use of a computer simulation to develop mental simulations for understanding relative motion concepts. International Journal of Science Education, v. 21, n. 9, p. 921-944, 1999.

MONTENEGRO, R.L.; PESSOA JR., O. Interpretações da Teoria Quântica e as Concepções dos Alunos do Curso de Física. Investigações sobre Ensino de Ciências, v. 7, n. 2, 2002.

MORAES, R; GALIAZZI, M. C. Análise Textual Discursiva. Ijuí: Editora Unijuí, 2007.

MOREIRA, M. A. Modelos mentais. Investigações em ensino de ciências, v. 1, n. 3, p. 193232, 1996.

MÜLLER, R.; WIESNER, H.. Teaching Quantum Mechanics on a introductory level. American Journal of Physics, 70, 3, 200-209, 2002.

OLSEN, R. V. Introducing quantum mechanics in the upper secondary school: a study in Norway, International Journal of Science Education. v. 24, n. 6, p. 565-574, 2002. 
PEREIRA, A.; OSTERMANN, F.; CAVALCANTI, C. J. H. On the use of a virtual Mach-Zehnder interferometer in the teaching of quantum mechanics. Physics Education, v. 44, n. 3, p. 281, 2009.

PESSOA JR, O. Conceitos de física quântica. São Paulo: Livraria da Física, v. 2. 2008.

PESSOA JR, O. Conceitos de física quântica. São Paulo: Livraria da Física, v. 1. 2006.

PESSOA JR, O. Interferometria, Interpretação e Intuição: uma Introdução Conceitual a Física Quântica. Revista Brasileira de Ensino de Física, v. 19, n. 1, 1997.

PIETROCOLA, M. Construção e Realidade: o realismo científico de Mário Bunge e o ensino de ciências através de modelos. Investigações em Ensino de Ciências, Porto Alegre, v. 4, n. 3, 1999.

SINGH, C; MARSHMAN, E. Review of student difficulties in upper-level quantum mechanics. Physical Review Special Topics-Physics Education Research, v. 11, n. 2, p. 020117, 2015.

SOUZA, B. C. A Teoria da Mediação Cognitiva: os impactos cognitivos da hipercultura e da mediação digital. 2004. 282 f. Tese (Doutorado em Psicologia), Universidade Federal de Pernambuco, Recife, 2004.

SINGH, Chandralekah. Interactive learning tutorials on quantum mechanics. American Association Of Physics Teachers. v. 76, abr.-maio, 2008. DOI: 10.1119/1.2837812.

SOUZA, B. C. et al. Putting the Cognitive Mediation Networks Theory to the test: Evaluation of a framework for understanding the digital age. Computers in Human Behavior, v. 007, p. 10.1016, 2012.

TAO, P. K.; GUNSTONE, R. F. A process of conceptual change in force and motion during computer-supported Physics instruction. Journal of Research in Science Teaching, v.3 7, n. 2, p. 859-882, 1999.

TREVISAN, R. Um estudo da relação entre as imagens mentais utilizadas por estudantes de mecânica quântica e seu perfil epistemológico: uma investigação pela metodologia Report Aloud. 169 f. Dissertação (Mestrado) - Ensino de Ciências e Matemática, Universidade Luterana do Brasil, Canoas, 2016.

TREVISAN, R.; SERRANO, A. A Utilização de Ferramentas Hiperculturais no Ensino de Mecânica Quântica: Investigação do Aprendizado de Representações, Drivers e Conceitos Quânticos. Revista Novas Tecnologias na Educação, v. 12, p. 1, 2014.

TREVISAN, R.; SERRANO, A. Uma construção do Perfil Epistemológico de licenciandos em Física acerca da dualidade onda-partícula em Mecânica Quântica, após o uso de bancadas virtuais: um estudo a partir do discurso gestual e verbal. Revista Novas Tecnologias na Educação, v. 14, n. 1, 2016.

TREVISAN, R.; SERRANO, A. Investigando os Drivers e as Representações Mentais Presentes nas Interpretações Privadas de Estudantes de Mecânica Quântica. Acta Scientiae, v. 20, n. 4, 2018.

WUTTIPROM, S. et al. Development and use of a conceptual survey in introductory quantum physics. International Journal of Science Education, v. 31, n. 5, p. 631-654, 2009. 